\title{
O Chaos das 5
}

\author{
Flávio Luiz Schiavoni, Adilson Siqueira, Rogério Tavares Constante, \\ Igino de Oliveira Silva Junior, Thiago de Andrade Morandi, Fábio dos Passos Carvalho, \\ João Teixeira Araújo, André Lucas Nascimento Gomes, Frederico Ribeiro Resende, \\ Luísa Lugon-Moulin Brazil Santos, Avner Maximiliano de Paulo, Carlos Eduardo Oliveira de Souza, \\ Allyson da Cruz Rodrigues, Igor Alves Estevam Andrade, Aneliza Rodrigues Prado, \\ Gabriel Lopes Rocha, Patrick Veniali da Silva, João Lucas Ruas Teixeira, Aretha Brito de Lima, \\ Bruna Guimarães Lima e Silva, Ívyla Nascimento Silva, Wanderson Andre Martins Pereira, \\ Rafael Gomes de Oliveira, Octávio Ferreira Deluchi Cerqueira da Silva, \\ Valdir de Siqueira Santos Junior, Matteo Vinicius Alves Recinella \\ ${ }^{1}$ Arts Lab in Interfaces, Computers, and Everything Else - ALICE \\ Nucleus of Art and Sustainability - NAST \\ Federal University of São João del-Rei \\ São João del-Rei, MG \\ flseufsj.edu.br
}

\begin{abstract}
O Chaos das 5" is an audiovisual digital performance. The guideline of the performance is inspired by Alice, from Lewis Carroll book - Alice in the Wonderland, as a metaphor to take the audience to a synthetic and disruptive wonder world. The concept of the performance is to conceive the possibility to the audience to interact through digital interfaces creating an immersive and participatory experience by combining three important layers of information (music, projections and gestures) through their cellphones. Once that the audience members take part of the show on an immersive aspect, there is no stage or another mark to limit the space of the performers and the audience.
\end{abstract}

\section{Introduction}

O Chaos das 5 is a piece of collective creativity developed by the Transdisciplinary research Group (GTRANS) from the Federal University of São João del-Rei involving the ALICE (Arts Lab in Interfaces, Computers and Else) / Orchidea (Orchestra of Ideas) group from the Computer Science Department and the ECOLAB / Movère group from the Scenic Arts Department.

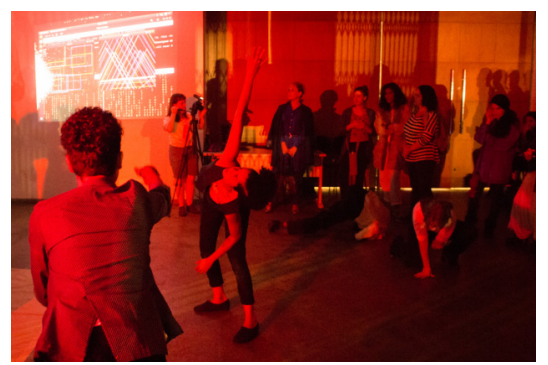

Figure 1: Performers and the audience

The guideline of the performance took Alice, from Lewis Carroll book - Alice in the Wonderland [1], as a metaphor to take audience to a synthetic and disruptive wonder world. The audience members could take part of the show and there is no stage or another mark to limit the space of the performers and the audience.
Three layers of information were used to create an immersive experience to the audience combining music, visual and gesture by the means of technology. Five musicians located around the space create the base of the sound using DMIs and over processed electric guitars. The audience members could participate of the sound using their cellphones and accessing a set of web DMI developed to this performance.

The visual layer used three projectors and some software developed in our lab to create images in real time. Here, the aesthetic approach is to break the Black Box [2] and show to the audience what is the technology behind the scene. The code of the software sometimes is also projected, like in a live coding [3] performance, and two programmers were changing the code and the visual on the fly. Images took by the audience members with their cellphones are also used in this layer and webcams and image processing in real time completed the visual set up.

The gestural layer is performed by artists interacting physically with the audience members in the space. In the beginning of the show it was probably not easy to identify who were the artists and who were audience members. This performatic artists merged gestural score and improvisation to interact among them and with audience members and their participation became more clear during the show.

\section{The plot}

We started the performance with the projection of a countdown clock and an invitation to the audience take part of the performance accessing a website. In the website, the audience members could find some instructions and instruments that could be used during the show. They could also inform their names and upload a picture to register their participation.

The first part of the performance is a synthetic universe, the dive in the rabbit hole, among synthetic images and infinite glissandos that remembers Metastasis from Xenakis. During this part, the performers that were 


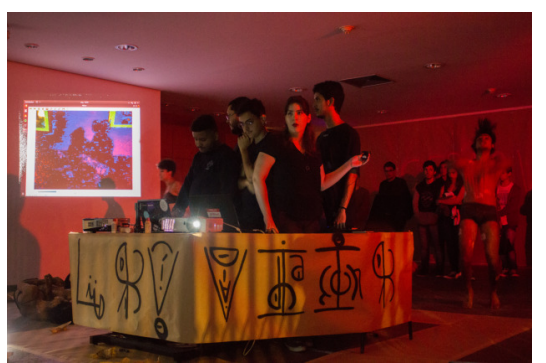

Figure 2: The live coding room

among the audience members started acting in a reverse form, revelling their selves as part of the performance and taking attention to them.

The free falling finishes in a second part, a disruptive experience in the real world. A territory battle in the city where people try to exist and register this existence guided this part of the performance. We projected a noisy sequence of pictures of graffiti and other urban scenes while a city soundscape completed a saturated urban scene. Performers started painting their selves using stickers and brushes and the audience members were invited to do the same.

To escape the reality and the tension of the second part, a third part took the audience to a surreal experience, calming down until the end. The performers, tired of the second scene, start a slow dance in front of the distorted projection of themselves.

At the end, like a credit film, a projection presents the name of all members of the performance including the audience members that filled their name and picture in the website.

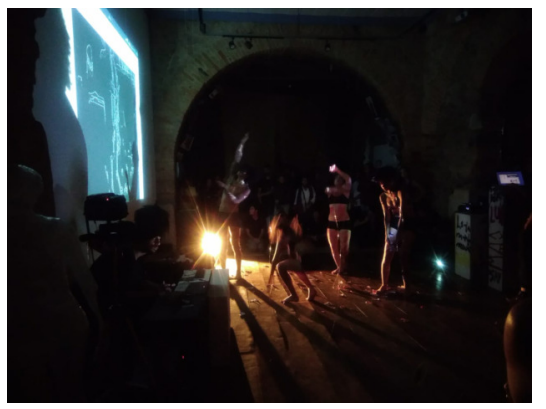

Figure 3: Performers interacting with projections

\section{The concepts}

The main line in this performance is about questioning realism and surrealism in the contemporary world when facing brute technology interacting with our bodies. The show update the notion of reality putting on the scene the precision of the digital media and the uncertain rhythm of machines in our lives. The concept of immersion in Virtual Reality implies in using machines hiding them from the people resulting in human beings being exposed to digital stimulus without noticing the presence of machines. In ubiquitous computing, the presence of machines is so deeply felt that machines can interact directly with humans beings being part of our reality.

That is the concept explored in our performance in our visual and musical layers. All the computers and live coders are present in the scene showing to the audience their screens and codes. Linux terminals commands, coding being compiled in real time, all these artifacts serve to break the barrier of the computer invisibility during the performance. Everything can be seen but it certainly does not make it easier to be understood. The unveiled machines increase discomfort but not necessarily increase the level of understanding. In the middle of all these unveiled technology, the performers and the audience deals with improvisation and the effect of technology in our daily lives.

Our musical layer is inspired in three contemporary composers: comes from glissandos inspired in Metastasis from Xenakis and Shepard tones, soundscapes composed to create a urban interaction environment, inspired from Murray Schafer, and a surrealist calm inspired by Olivier Messiaen.

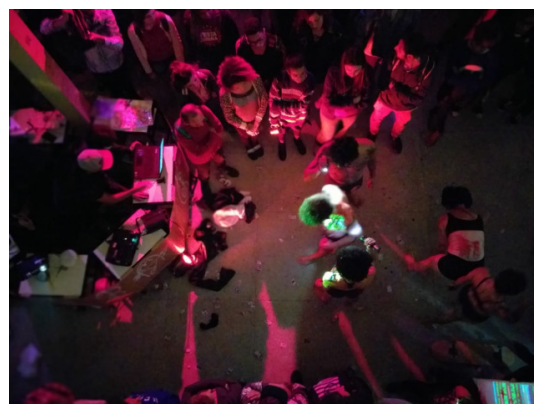

Figure 4: Performers, live coders and audience

This improvisation environment lead us to several questions: A mistake is really a mistake? When is it considered part of the show? What is the limit to improvisation and a programmed manner to work? Our narrative is uncertain and a distance from what is hermetic and finished is what we try to reach as our main theoretical goal.

\section{Acknowledgments}

Authors would like to thanks to all ALICE and Movère members that made this research and development possible. The authors would like also to thank the support of the funding agencies CNPq and FAPEMIG and the support of the PROEX - UFSJ.

\section{References}

[1] Lewis Carroll. Alice Adventures in Wonderland \& Through the Looking-Glass. CreateSpace Independent Publishing Platform, 2018.

[2] Vilem Flusser. O Mundo Codificado (Em Portuguese do Brasil). Cosac \& Naify, 2007.

[3] Nick Collins, Alex McLean, Julian Rohrhuber, and Adrian Ward. Live coding in laptop performance. Organised sound, 8(3):321-330, 2003. 